STUDI

FRANCESI

\section{Studi Francesi}

Rivista quadrimestrale fondata da Franco Simone

165 (LV | III) | 2011

LA RAPPRESENTAZIONE DELLA MADRE NELLA

LETTERATURA FRANCESE DEL NOVECENTO a cura di Dario Cecchetti e Michele Mastroianni

\title{
Twentieth-Century French Poetry. A Critical Antho-logy, edited by Hugues Azérad and Peter Collier
}

\section{Fabio Scotto}

\section{(2) OpenEdition \\ Journals}

Edizione digitale

URL: http://journals.openedition.org/studifrancesi/5147

DOI: $10.4000 /$ studifrancesi.5147

ISSN: 2421-5856

Editore

Rosenberg \& Sellier

Edizione cartacea

Data di pubblicazione: 1 décembre 2011

Paginazione: 679

ISSN: 0039-2944

Notizia bibliografica digitale

Fabio Scotto, «Twentieth-Century French Poetry. A Critical Antho-logy, edited by Hugues Azérad and Peter Collier», Studi Francesi [Online], 165 (LV | III) | 2011, online dal 30 novembre 2015, consultato il 13 janvier 2021. URL: http://journals.openedition.org/studifrancesi/5147 ; DOl: https://doi.org/10.4000/ studifrancesi.5147

Questo documento è stato generato automaticamente il 13 janvier 2021.

\section{(†) $\ominus$

Studi Francesi è distribuita con Licenza Creative Commons Attribuzione - Non commerciale - Non opere derivate 4.0 Internazionale. 


\title{
Twentieth-Century French Poetry. A Critical Antho-logy, edited by Hugues Azérad and Peter Collier
}

\author{
Fabio Scotto
}

\section{NOTIZIA}

Twentieth-Century French Poetry. A Critical Antho-logy, edited by Hugues AZÉRAD and Peter COLLIER, New York, Cambridge University Press, 2010, pp. XXV-330.

1 Il progetto antologico dei Curatori ha l'indubbio intento pedagogico di proporre a un pubblico vasto e prevalentemente studentesco una scelta di poeti francesi novecenteschi commentati da alcuni dei più significativi critici contemporanei del settore, in larga parte di area anglosassone, ma con qualche contributo di critici francesi che si esprimono in inglese (come Jean-Pascal Pouzet o Jean Khalfa), o che sono proposti in traduzione (è, ad esempio, il caso di Jean-Michel Maulpoix). Il volume si apre con un saggio introduttivo di Yves BonNeFoy (Foreword: Ending the Mission, Inaugurating the Pact, pp. XIX-XXV) non scritto appositamente per il volume, ma scelto dai Curatori come spunto utile di riflessione generale sulla natura della poesia d'oggi; in esso Bonnefoy mostra i tratti peculiari della sua poetica critica, dalla lotta fra il concetto e la presenza all'esigenza di fondare una poesia immune dalla tentazione di farsi missione o mera espressione artistica e che fondi sul potere del suono e sull'evocazione dell'infanzia la sua trascendenza immanente, la sua capacità di verità oltre ogni illusione. Hugues AzÉRAD, nella sua General Introduction (pp.1-13), si muove nel solco del testo di Bonnefoy per avvalorare la scelta di aver evitato, come da questi propugnato, il rischio di fare dell'analisi della poesia un mezzo per confermare credenze o idee preconcette sulla poesia del critico, a profitto semmai della più ampia libertà di approccio da parte dei commentatori coinvolti nel progetto, ai quali è anche stato lasciato il compito di liberamente selezionare il testo da commentare. 
Come successivamente illustra Azérad, l'antologia è composta di quattro parti, «Traditions and Modernisms» (da Valéry a Senghor), «Avant-Gardes» (da Reverdy a Ponge), «Poetics of Presence» (da Char a Glissant) e «New Voices, New Visions» (da Deguy ad Alferi), per un totale di trentadue poeti selezionati, di ognuno dei quali è proposto un brano commentato, seguito da una breve Bibliografia critica specifica sull'Autore. I commenti forniscono indicazione generali sul poeta in questione di cui poi analizzano il testo secondo un approccio testuale e stilistico ora d'impianto retorico ora fenomenologico, con adeguata tecnicità e precisione di rimandi e rilievi che hanno spesso il pregio di contestualizzare la riflessione nell'àmbito dell'epoca e della ricerca coeva. Come per ogni antologia, genere opinabile per eccellenza, si potrebbe disquisire sulle presenze e assenze, il che condurrebbe a un lungo elenco di esclusi (da Artaud a Bataille a Desnos) forse più importanti a nostro avviso di alcuni autori inclusi, ma nella soggettività di ogni provvisorio canone più importante della comunque irraggiungibile esaustività di ogni scelta è senz'altro l'idea d'assieme e l'approccio critico globale che le è sotteso, qui meno storico che pedagogico, almeno così a noi pare. Se difficilmente da un solo brano è possibile davvero cogliere la valenza poetica di un autore è pur anche vero che è forse preferibile un commento ampio e argomentato a una sequenza di brevi noterelle a chiosa di più brani, come spesso nelle antologie accade. In appendice Clive scotT (Afterword: Reading Twentieth-Century French Verse, pp. 288-294) dà conto dell'evoluzione della modalità di riproduzione vocale della poesia nel corso del secolo, così come della versificazione, con alcuni esempi salienti da Apollinaire, Calaferte e du Bouchet. Chiudono il volume una sezione di Biographies of the Poets (pp. 295-311), un utile Glossary (pp. 312-318) e una Select Bibliography (pp. 319-327). 